\title{
Triple therapy combined with ventriculoperitoneal shunts can improve neurological function and shorten hospitalization time in non-HIV cryptococcal meningitis patients with increased intracranial pressure
}

Min $\mathrm{Li}^{1+}$, Jia Liu ${ }^{1+}$, Xuhui Deng ${ }^{2+}$, Qingzhou Gan ${ }^{1}$, Yijie Wang ${ }^{1}$, Xiaofeng $X u^{1}$, Ying Jiang ${ }^{1}$ and Fuhua Peng ${ }^{1 *}$

\begin{abstract}
Background: Raised intracranial pressure (ICP) and insufficient antifungal regimens are the two main factors result to unsatisfactory outcomes in non-HIV cryptococcal meningitis (CM) patients. In this study, we try to discuss that whether triple therapy of amphotericin B (AmB), fluconazole, 5-flucytosine (5-FC) plus ventriculoperitoneal shunts (VPS) is superior to AmB, 5-FC, fluconazole plus intermittent lumbar puncture in induction therapy in non-HIV CM patients with increased ICP.

Methods: We reviewed 66 clinical records from non-HIV CM patients with increased ICP. The demographic and clinical characteristics, BMRC staging, cerebrospinal fluid profiles (CSF), brain magnetic resonance imaging, treatment, and outcomes of these individuals were retrospectively analyzed. All non-HIV CM patients with increased ICP ( $\geq 25 \mathrm{cmH2O}$ ) were divided into two groups, including 27 patients treated with triple antifungal agents and 39 patients treated with the same triple therapy plus VPS.

Results: Triple therapy plus VPS group had more satisfactory outcomes, more CSF sterilization at 10 weeks followup, lower CSF opening pressure, lower BMRC staging scores one week after VPS, less CSF C. neoformans counts and CSF culture positive. Besides, these patients had shorter hospital stay than triple therapy group.

Conclusions: Triple antifungal agents combined with VPS could effectively reduce ICP, had faster rate of clearance of $C$. neoformans counts, more improved neurological function, shorten hospitalization time and better outcomes in non-HIV CM patients with increased ICP. Our study indicated that triple therapy plus early VPS may be an optimal treatment for non-HIV CM patients with increased ICP.
\end{abstract}

Keywords: Triple therapy, Ventriculoperitoneal shunts, Non-HIV cryptococcal meningitis, Increased intracranial pressure

\footnotetext{
* Correspondence: pengfh@mail.sysu.edu.cn

${ }^{\dagger}$ Min Li, Jia Liu and Xuhui Deng contributed equally to this work.

'Department of Neurology, The Third Affiliated Hospital of Sun Yat-Sen University, Guangzhou 510630, Guangdong, China

Full list of author information is available at the end of the article
}

(c) The Author(s). 2020 Open Access This article is licensed under a Creative Commons Attribution 4.0 International License, which permits use, sharing, adaptation, distribution and reproduction in any medium or format, as long as you give appropriate credit to the original author(s) and the source, provide a link to the Creative Commons licence, and indicate if changes were made. The images or other third party material in this article are included in the article's Creative Commons. licence, unless indicated otherwise in a credit line to the material. If material is not included in the article's Creative Commons licence and your intended use is not permitted by statutory regulation or exceeds the permitted use, you will need to obtain permission directly from the copyright holder. To view a copy of this licence, visit http://creativecommons.org/licenses/by/4.0/. The Creative Commons Public Domain Dedication waiver (http://creativecommons.org/publicdomain/zero/1.0/) applies to the data made available in this article, unless otherwise stated in a credit line to the data. 


\section{Background}

Cryptococcal meningitis (CM) is one of the most common clinical presentations of cryptococcosis, which accounts for more than 223,100 cases and 181,100 deaths per year [1]. Elevated intracranial pressure (ICP) is the most common complication of CM, and can cause impaired mental status, neurological deterioration, and severe disability $[2,3]$.

The Infectious Diseases Society of America (IDSA) recommended the induction therapy of amphotericin $B$ deoxycholate $(\mathrm{AmB})(0.7-1.0 \mathrm{mg} / \mathrm{kg}$ per day) combining with 5 -flucytosine (5-FC) $(100 \mathrm{mg} / \mathrm{kg}$ per day) for at least 4 weeks as the preferred regimen for non-HIV-infected and non-transplant patients with CM [4]. However, $\mathrm{AmB}$ and 5-FC may often cause severe toxic effects so that CM patients can't endure the recommended dosages. In addition, increased ICP $\left(\geq 25 \mathrm{~cm} \mathrm{H}_{2} \mathrm{O}\right)$ in $\mathrm{CM}$ patients, is associated with short-term survival and impaired treatment response [5]. Raised ICP and only moderately effective antifungal regimens, which frequently take more than 4-6 weeks to sterilize cerebrospinal fluid (CSF), are two main factors that result to unsatisfactory outcomes in CM patients [6]. Despite therapy, mortality rates in HIV-seronegative individuals with $\mathrm{CM}$ are high [7]. Our previous study showed that non-HIV patients with triple therapy of $\mathrm{AmB}, 5-\mathrm{FC}$ plus Fluconazole at sub-therapeutic doses seemed to have a better prognosis than therapy of AmB and Fluconazole [8], and early placement of ventriculoperitoneal shunts (VPS) is helpful in decreasing ICP and fungal overload in non-HIV CM patients [9]. Aggressive management of ICP combined with antifungal therapy is possible the optimal treatment [10]. Therefore, we try to discuss that whether triple therapy of $\mathrm{AmB}, 5-\mathrm{FC}$, fluconazole plus VPS is superior to AmB, 5-FC, fluconazole plus intermittent lumbar puncture in induction therapy in non-HIV CM patients with increased ICP.

\section{Materials and methods}

In this study, data were derived from $66 \mathrm{CM}$ patients enrolled from January 2011 to December 2018 at the Third Affiliated Hospital of Sun Yat-sen University, Guangzhou, China. CM patients were identified by symptoms and signs, and positive India ink staining of the CSF or a positive CSF culture for Cryptococcus neoformans. All patients were confirmed to be non-HIV infected, with CSF opening pressure $\geq 25 \mathrm{cmH}_{2} \mathrm{O}$. These selected $\mathrm{CM}$ patients were divided into two groups according to the treatment regimens. In triple therapy group, the 27 patients were treated with a combination of AmB, fluconazole, and 5FC plus intermittent lumbar puncture. In triple therapy plus VPS group, the 39 patients were administered triple therapy of AmB, fluconazole, and 5-FC plus VPS. Patients meeting one of the following criteria were excluded: (1) prior surgical intervention due to intracranial hypertension; (2) recurrent CM.

The demographic and clinical characteristics, British Medical research council (BMRC) staging [11], CSF profiles, brain magnetic resonance imaging (MRI), treatment, and outcomes of these individuals were analyzed. The BMRC staging system was used to evaluate the severity in this study. We compared the two groups at baseline levels, discharge and follow-up at 10 weeks. The enrolled patients underwent lumbar punctures at least once a week in accordance with guidelines during the implementation of the two study regimens $[5,12]$. CSF specimens were routinely evaluated for white blood cell (WBC) counts, glucose, protein, India ink stain and culture. Other conventional blood tests and images were also recoreded during treatment.

The antifungal therapy was initiated as soon as the diagnosis of CM confirmed. In triple therapy group, the patients were treated with intravenous AmB (30-40 mg/ d), fluconazole $(600-800 \mathrm{mg} / \mathrm{d})$ plus oral 5-FC (4-6 g/d) daily for at least 2 weeks. In triple therapy plus VPS group, the patients received the same triple therapy for at least 2 weeks, and received VPS. The CM treatment response in this study was defined by clinical and mycological criteria [13], particularly the documented clearance of the CSF [14]. The outcome of treatment response was assessed at 10 weeks after the initiation of antifungal therapy. Based on the CSF cryptococcus clearance, the therapeutic outcomes were divided as 'successful response'(including complete response and partial response) or 'failure'(including stable response, disease progression and death) [15].

Continuous variables (presented as the mean \pm standard deviation (SD) or median with ranges) were performed with a t-test or Wilcoxon rank sum test. Categorical variables (expressed as a percentage) were used with Chi-square test, Fisher's exact test or Wilcoxon rank sum test.

Significance was set at $P<0.05$. Laboratory data were analyzed as factors using univariate and multivariate analyses in both groups for the outcome analysis. All statistical analyses were two-sided and performed using SPSS (version 16.0, Chicago, IL, USA) .

\section{Results}

The demographics, baseline CSF parameters, cranial computed tomography (CT)/MRI and baseline BMRC staging of the patients were presented in Table 1. Triple therapy plus VPS group patients had higher burdens of cryptococcal in organisms at baseline (median 9533 vs. 1398 C. neoformans counts $/ \mathrm{ml}$, respectively, $P=0.002$ ), and shorter hospital stay than that of triple therapy group (77 vs. $35, P=0.000$ ). That meant triple antifungal agents combined with VPS could obviously shorten the 
Table 1 Baseline patient characteristics

\begin{tabular}{|c|c|c|c|}
\hline Variables & $\begin{array}{l}\text { Group I (AmB+ Fluconazole } \\
+5-\mathrm{FC}, n=27)\end{array}$ & $\begin{array}{l}\text { Group II (AmB+ Fluconazole } \\
+5-F C+\text { VPS, } n=39 \text { ) }\end{array}$ & $P$-value \\
\hline Age, years (mean $\pm S D$ ) & $44.1 \pm 14.0$ & $47.9 \pm 14.7$ & 0.287 \\
\hline Gender, male $(n, \%)$ & $20(74.1 \%)$ & $28(71.8 \%)$ & 0.839 \\
\hline \multicolumn{4}{|l|}{ Predisposing Factors } \\
\hline Chronic hepatitis B & $5(18.5 \%)$ & $4(10.3 \%)$ & 0.340 \\
\hline Pulmonary tuberculosis & $3(11.1 \%)$ & $2(5.1 \%)$ & 0.370 \\
\hline Type 2 diabetes mellitus & $2(7.4 \%)$ & $5(12.8 \%)$ & 0.486 \\
\hline Autoimmune diseases & $1(3.7 \%)$ & $4(10.3 \%)$ & 0.326 \\
\hline Solid tumor & $1(3.7 \%)$ & $4(10.3 \%)$ & 0.326 \\
\hline Symptoms duration, days, (med, range) & $30(6-120)$ & $30(8-90)$ & 0.331 \\
\hline Length of hospital stay days, (med, range) & $77(12-308)$ & $35(18-73)$ & $0.000^{*}$ \\
\hline \multicolumn{4}{|l|}{ CSF parameters opening pressure } \\
\hline$\geq 25 \mathrm{cmH} 2 \mathrm{O}(\mathrm{n}, \%)$ & $27(100 \%)$ & $42(93.0 \%)$ & 0.107 \\
\hline CSF WBC count×106/l (med, range) & $92(10-649)$ & $82(4-840)$ & 0.744 \\
\hline$\geq 20(n, \%)$ & $23(85.2 \%)$ & $32(82.1 \%)$ & 0.871 \\
\hline CSF protein g/l (med, range) & $0.78(0.08-2.58)$ & $0.71(0.22-5.10)$ & 0.579 \\
\hline CSF glucose mmol/I (med, range) & $1.19(0.00-3.79)$ & $0.83(0.01-3.09)$ & 0.273 \\
\hline CSF cryptococci count/ml (med, range) & $1398(0-57,500)$ & $9533(0-263,000)$ & $0.002^{*}$ \\
\hline CSF culture positive $(+)$ & $15(55.69 \%)$ & $19(48.7 \%)$ & 0.114 \\
\hline \multicolumn{4}{|l|}{ Brain images (CT or MRI) } \\
\hline Meningeal enhancement & $18(66.7 \%)$ & $18(46.2 \%)$ & 0.182 \\
\hline Cryptococcosis-related lesions in brain & $13(48.1 \%)$ & $17(43.6 \%)$ & 0.717 \\
\hline Hydrocephalus & $3(11.1 \%)$ & $3(7.7 \%)$ & 0.637 \\
\hline BMRC staging $(n, \%)$ & & & 0.443 \\
\hline 1 & $2(7.4 \%)$ & $8(20.5 \%)$ & \\
\hline 2 & $16(59.3 \%)$ & $10(25.6 \%)$ & \\
\hline 3 & $9(33.3 \%)$ & $21(53.8 \%)$ & \\
\hline
\end{tabular}

$A m B$ amphotericin B, 5-Fc flcytosine, VPS ventriculoperitoneal shunts, WBC white blood cell, SD standard deviation, med median, CSF cerebrospinal fluid, BMRC British Medical research council. Data are presented as the mean $\pm \mathrm{sD}$, median (range) or $\mathrm{n}(\%)$. Continuous variables were analyzed by t-test or Wilcoxon rank sum test; categorical variables were analyzed by Chi-square test or Fisher's exact test.

"P $P<0.05$

hospitalization time in non-HIV CM patients with increased ICP $\left(\geq 25 \mathrm{cmH}_{2} \mathrm{O}\right)$.

The results of CSF sterilization within 10 weeks between the two groups were detailed in Table 2. Compared to triple therapy group, there were more patients in triple therapy plus VPS group to clear cryptococcus from the CSF $(P=0.033)$, which suggested that triple antifungal agents plus VPS could more effectively clear cyptococcus from CSF. No significant differences were observed in the early fungicidal activity (CSF sterility within 2 weeks) and persistent infection (CSF sterility beyond 4 weeks [4]) between the two groups.

The CSF opening pressure, CSF C. neoformans counts and CSF culture positive of patients in triple therapy plus VPS group significantly decreased after VPS $(P=$ $0.000, P=0.019$ and $P=0.002$, respectively). CSF protein increased significantly after VPS. Patients in triple therapy plus VPS group got the improvement in neurological function circumstances evaluated by comparing the BMRC staging before and after VPS $(P=0.026)$ (Table 3$)$, which suggested that triple antifungal agents combined with VPS could significantly improve neurological function.

Adverse events were common. Antifungal drugs are associated with toxic effects, particularly AmB and 5-FC. At the end of the 10th week, there were no significant differences in the two groups in objective blood tests (Table 4). Sequelae was mainly headache and cranial nerve deficit (optic and auditory nerves). No significant differences about sequelae in two groups were found.

In triple therapy plus VPS group, after the VPS, thirteen cases had low to moderate fever, and the 
Table 2 Data for the CSF sterility at the 10 weeks follow-up

\begin{tabular}{|c|c|c|c|}
\hline & $\begin{array}{l}\text { Group I (AmB+ } \\
\text { Fluconazole+ 5-FC,n=27) }\end{array}$ & $\begin{array}{l}\text { Group II (AmB + } \\
\left.\text { Fluconazole+5-FC + VPS, } n^{\mathrm{a}}=38\right)\end{array}$ & $\begin{array}{l}P \text { - } \\
\text { value }\end{array}$ \\
\hline case $(n, \%)$ & $8(29.6 \%)$ & $22(56.4 \%)$ & $0.033^{*}$ \\
\hline Days $^{\mathrm{b}}($ mean $\pm \mathrm{SD})$ & $29.2 \pm 20.0$ & $32.5 \pm 24.8$ & 0.909 \\
\hline$\leq 2$ weeks $(n, \%)$ & $2(7.4 \%)$ & $8(20.5 \%)$ & 0.662 \\
\hline$>2$ weeks $(n, \%)$ & $6(22.2 \%)$ & $14(35.9 \%)$ & \\
\hline$\leq 4$ weeks $(n, \%)$ & $4(14.8 \%)$ & $13(33.3 \%)$ & 0.730 \\
\hline$>4$ weeks $(n, \%)$ & $4(14.8 \%)$ & $9(23.1 \%)$ & \\
\hline
\end{tabular}

$A m B$ amphotericin B, 5-Fc flucytosine, Flu fluconazole, SD standard deviation. Continuous variables analyzed by t-test; categorical variables analyzed by chi-square test or Fisher's exact test

${ }^{\text {a }}$ One patient was lost to -follow-up at the 10th week in Group II

${ }^{b}$ 'Days' indicates the time from diagnosis to the first negative CSF india ink stain ${ }^{*} P<0.05$

temperature recovered to normal in a week by using antibiotics. One case occured shunt obstruction and he was taken second operation on the other side. One case turned up excessive shunt after operation, and his CSF open pressure was normal by adjust the drainage tube. There was no cryptococcal infection spread to other organs (Table 3).

The primary outcome of treatment response was evaluated at the 10th week after the initial therapy. The total 'successful response' rate (including complete and partial responses) in triple therapy plus VPS group reached 57.9\% $(22 / 38)$, whereas the rate was $29.6 \%(8 / 27)$ in triple therapy group $(P=0.025)$ (Table 5 and Fig. 1$)$. Two patients in triple therapy plus VPS group died of multiple organ failure on the 18st day and 47st day respectively. One patient died in triple therapy group after the 10 weeks. Triple therapy plus VPS group patients have shorter the first hospitalization stay than triple therapy group (Fig. 2, log Rank $\mathrm{p}<0.000$ ). In the multivariate analysis, we did not find meaningful predictors of an satisfactory outcome in the triple therapy group. The multivariate analysis showed high red blood cells levels (OR 3.210, 95\% CI 1.097-9.396; $P=0.033)$ to be a good prognosic factor for the patients with triple therapy plus VPS (Table 6).

\section{Discussion}

In this study, we found that triple antifungal agents combined with VPS could effectively reduce ICP, had

Table 3 Clinical characteristics of Group II patients before VPS and one weeks after VPS

\begin{tabular}{|c|c|c|c|}
\hline Patient & Before VPS & one week after VPS & $P$-value \\
\hline \multicolumn{4}{|l|}{ CSF parametersopening pressure } \\
\hline$\geq 25 \mathrm{mH} 2 \mathrm{O}(\mathrm{n}, \%)$ & $33(84.6 \%)$ & $12(30.8 \%)$ & $0.000^{*}$ \\
\hline CSF WBC count×106/l (med, range) & $66(4-620)$ & $77(0-993)$ & 0.220 \\
\hline$\geq 20(n, \%)$ & $36(80.0 \%)$ & $41(91.1 \%)$ & 0.136 \\
\hline CSF protein g/l (med, range) & $0.67(0.22-4.08)$ & $2.29(0.08-729)$ & $0.000^{*}$ \\
\hline CSF glucose mmol/I (med, range) & $1.16(0.01-3.47)$ & $0.91(0.01-4.86)$ & 0.380 \\
\hline CSF cryptococci count/ml (med, range) & $9533(0-263,000)$ & $2066(0-235,000)$ & $0.019^{*}$ \\
\hline CSF culture positive $(+)(n, \%)$ & $19(48.7 \%)$ & $6(15.4 \%)$ & $0.002^{*}$ \\
\hline BMR staging $(n=39)$ & & & $0.026^{*}$ \\
\hline 1 & $8(20.5 \%)$ & $14(35.9 \%)$ & \\
\hline 2 & $10(25.6 \%)$ & $14(35.9 \%)$ & \\
\hline 3 & $21(53.8 \%)$ & $11(28.2 \%)$ & \\
\hline Complications after VSP (n, \%) & NA & $20(44.4 \%)$ & NA \\
\hline Fever 3 days after VPS & NA & $16(35.6 \%)$ & NA \\
\hline Over-shunting & NA & $2(4.4 \%)$ & NA \\
\hline Obstructed shunt & NA & $3(6.7 \%)$ & NA \\
\hline Secondary abdominal infection & NA & 1 (2.2\%) & NA \\
\hline
\end{tabular}

VPS ventriculoperitoneal shunts, WBC white blood cell, med median, CSF cerebrospinal fluid, NA not available. Data are presented as median (range) or $\mathrm{n}$ (\%). Categorical variables were analyzed by Chi-square test or Fisher's exact test 
Table 4 Adverse events in objective blood tests during the treatment and sequelae at the 10th week in patients between group I and group II

\begin{tabular}{llll}
\hline & $\begin{array}{l}\text { Group I (AmB+ } \\
\text { Fluconazole + 5-FC) }\end{array}$ & $\begin{array}{l}\text { Group II (AmB+ } \\
\text { Fluconazole + 5-FC+ VPS) }\end{array}$ \\
\hline Adverse events (n, \%) & $(n=27)$ & $(n=39)$ & $20(51.3 \%)$ \\
Hypokalemia & $13(48.1 \%)$ & $15(38.5 \%)$ & 0.804 \\
Transaminase elevation & $14(51.9 \%)$ & $12(30.8 \%)$ & 0.285 \\
Renal impairment & $5(18.5 \%)$ & $14(35.9 \%)$ & 0.267 \\
Hematological impairment & $5(18.5 \%)$ & $\left(n^{\mathrm{a}}=36\right)$ & 0.128 \\
Sequelae & $(n=27)$ & $9(25.0 \%)$ & 0.395 \\
Headache & $9(33.3 \%)$ & $5(13.9 \%)$ & 0.465 \\
Dizziness/vertigo & $2(7.4 \%)$ & $5(13.9 \%)$ & 0.850 \\
Hemiparesis & $4(14.8 \%)$ & $6(16.7 \%)$ & 0.184 \\
Visual & $8(29.6 \%)$ & $7(19.4 \%)$ & 0.077 \\
Auditory & $1(3.7 \%)$ & $2(5.6 \%)$ & 0.387 \\
Seizure & $3(11.1 \%)$ & & \\
\hline
\end{tabular}

a One patient was lost to -follow-up and two patients were death at the 10th week in Group II

faster rate of clearance of Cryptococcus, more improved neurological function, shorten hospitalization time and better outcomes in non-HIV CM patients with elevated ICP $\left(\geq 25 \mathrm{cmH}_{2} \mathrm{O}\right)$ than triple therapy group. No significant differences were observed in the incidence of adverse events and sequelae between the two groups.

As stated in our previous study [8], there were several reasons for patients treating with triple therapy. Patients could not bear $\mathrm{AmB}$ and 5-FC at the recommended doses from the beginning and (or) could not be maintained at the effective dose during induction therapy because of drug toxic effects $[4,16]$. Previous research had suggested early mycological clearance was favored with $\mathrm{AmB}$ deoxycholate plus fluconazole combination therapy [17]. Although AmB and fluconazole are theoretically antagonistic drugs, in vitro and clinical observations support the effectiveness of the combination $[6,18,19]$. Fluconazole in triple therapy administered at a conventional dosage may have compensated for the less role of $\mathrm{AmB}$ at lower dosage, particularly when fluconazole is combined with 5-FC [20]. Patients enrolled in this study were treated with triple therapy at conventional or subtherapeutic doses for the induction treatment. And no significant adverse events were found in objective blood tests during the treatment between two groups.

Elevated ICP is an important risk factor for high mortality and poor outcomes in CM patients [21, 22]. Among patients with uncontrollable increased ICP, the best way to decrease the pressure is to implant a permanent shunt [23]. VPS can effectively reduce ICP. The complications after VPS were controllable. Neurological function assessment by BMRC stage, was significantly improved after VPS. But the sequelae of the triple therapy plus VPS group wasn't significantly less than the triple therapy group. We proposed that early placement of a VPS is helpful in preventing irreversible neurological complications. Increased ICP $\left(\geq 25 \mathrm{cmH}_{2} \mathrm{O}\right)$ is a severe complication in patients with $\mathrm{CM}$, and is

Table 5 Treatment outcomes in patients between group I and group II at 10 weeks

\begin{tabular}{llll}
\hline & $\begin{array}{l}\text { Group I (AmB+ } \\
\text { Fluconazole + 5-FC, } \boldsymbol{n = 2 7 )}\end{array}$ & $\begin{array}{l}\text { Group II (AmB+ } \\
\text { Fluconazole + 5-FC+ VPS, } \boldsymbol{n = 3 9 )}\end{array}$ \\
\hline Lost to follow-up & $0(0.0 \%)$ & $1(2.3 \%)$ & 0.399 \\
Successful response & $8(29.6 \%)$ & $22(57.9 \%)$ & $0.025^{*}$ \\
Complete response & $3(11.1 \%)$ & $11(28.9 \%)$ \\
Partial response & $5(18.5 \%)$ & $11(28.9 \%)$ \\
Failure & $19(70.4 \%)$ & $16(42.1 \%)$ \\
Stable response & $15(55.6 \%)$ & $10(26.3 \%)$ \\
Disease progression & $4(14.8 \%)$ & $4(10.5 \%)$ \\
Death & $0(0.0 \%)$ & $2(5.3 \%)$ \\
\hline
\end{tabular}

$\bar{p} p<0.05$ 


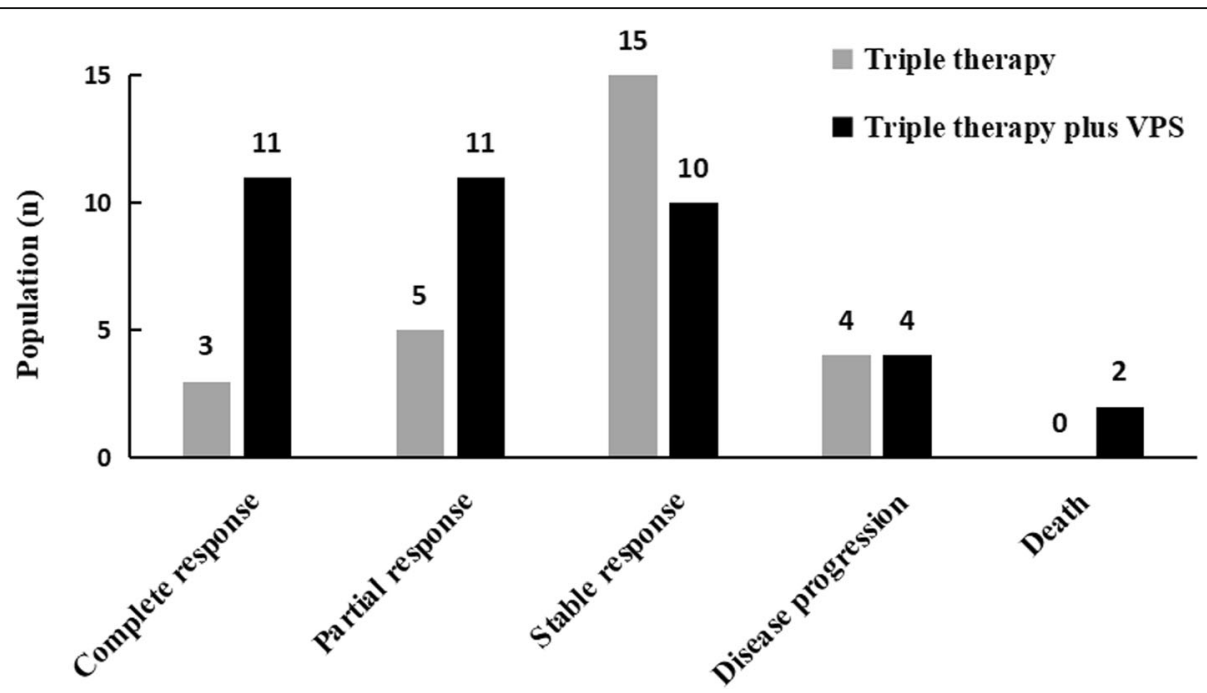

Fig. 1 Treatment outcomes according to induction therapy at the 10th week after the initial therapy

generally considered to relate to high fungal burden in the CSF and high mortality in CM $[6,24,25]$. A negative CSF culture at the end of the induction phase is an important predictor of fungal clearance at 10th week [26]. The goal of CM with ICP treatment is to reduce fungal burden quickly and to prevent long-term neurological deficits. In this study, triple therapy plus VPS group had faster rate of clearance of Cryptococcus than triple therapy group. Hung $\mathrm{CW}$ et al. reported that the mean hospitalization duration was 74.7 days and 70.6 days and interval between meningitis onset to shunting procedure was 68.7 days and 38.7 days for CM patients placed VPS with and without CSF over drainage, respectively [27]. Triple therapy group in our study had the similar result of hospital stay 77 days. Hospital stay of triple therapy plus VPS group was significantly shortened (35 days), which may be result of triple antifungal agents and early VPS. CM patients with elevated ICP who placing a VPS could be explained for following factors. CM patients had a typical presentation with substantially increased ICP along with severe headaches, nausea and vomiting, loss of consciousness, marked visual and auditory changes. Patients responded poorly for intermittent lumbar puncture to decrease the ICP or required continuous lumbar CSF drainage to remain neurologically asymptomatic. Patients in triple therapy plus VPS group mostly emerged aggravated symptoms or new symptoms in a short time before VPS. In addition, the timing and

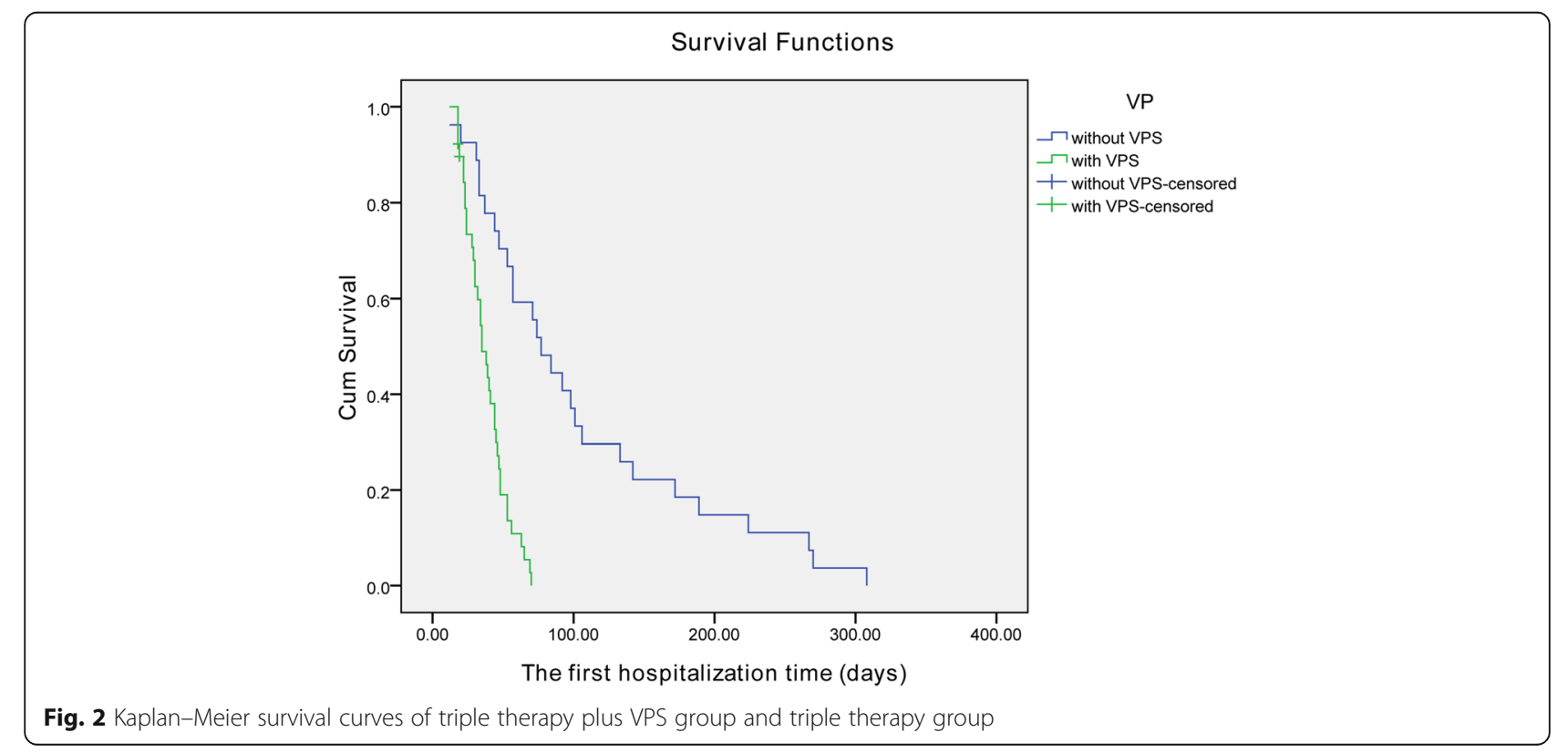


Table 6 Factors associated with satisfactory outcomes after treatment of triple therapy group and triple therapy plus VPS group

\begin{tabular}{|c|c|c|c|c|c|c|}
\hline \multirow[t]{2}{*}{ Variables } & \multicolumn{3}{|c|}{ Univariate analysis } & \multicolumn{3}{|c|}{ Multivariate analysis } \\
\hline & $\overline{O R}$ & $95 \% \mathrm{Cl}$ & $\overline{p \text {-Value }}$ & $\overline{\mathrm{OR}}$ & $95 \% \mathrm{Cl}$ & $p$-Value \\
\hline \multicolumn{7}{|l|}{ Group I } \\
\hline CSF protein & 4.924 & $0.855-28.354$ & 0.074 & & & \\
\hline CSF culture & 9.625 & $0.980-94.540$ & 0.052 & & & \\
\hline \multicolumn{7}{|l|}{ Group II } \\
\hline Red blood cells & 2.880 & $1.043-7.957$ & 0.041 & 3.210 & $1.097-9.396$ & 0.033 \\
\hline Blood creatinine & 1.046 & $1.000-1.094$ & 0.050 & & & \\
\hline
\end{tabular}

choice of VPS placement may be related to preferences of neurosurgery or physicians [28]. Recent study indicated that early shunt surgery is mandatory for the treatment of CM complicated by hydrocephalus and/or increased ICP to avoid irreversible neurological complications [27]. In our study, patients received VPS after admission with triple therapy, with lower CSF pressure, faster reduction of CSF C. neoformans counts. Baddley et al.'s study also suggested that earlier permanent VPS placement and more aggressive treatment may potentially improve outcomes for CM patients with increased ICP [28]. Treatment in triple therapy plus VPS group decreased the CSF pressure, CSF C. neoformans counts quickly, and certainly resulted to more 'successful response' rate (including complete and partial responses) than that in triple therapy group at 10 weeks follow-up.

Our study was performed in a single hospital by retrospective review of the medical records. The number of patients enrolled was small, and the dosage range of the three antifungal drugs was insufficient. Large multicenter real-life studies are needed to further verify the efficiency and feasibility of this method.

\section{Conclusions}

In summary, based our previous work, triple antifungal agents combined with VPS group could effectively reduce ICP, had faster rate of clearance of Cryptococcus, more improved nerve function, shorten hospitalization time and better outcomes in non-HIV CM patients with elevated ICP than triple therapy group. It is an optimal treatment with aggressive management of intracranial pressure and induction therapy with antifungal combination in non-HIV CM patients with intracranial hypertension $\left(\geq 25 \mathrm{cmH}_{2} \mathrm{O}\right)$.

\footnotetext{
Abbreviations

ICP: Intracranial pressure; CM: Cryptococcal meningitis; AmB: Amphotericin B; 5-FC: 5-flucytosine; CSF: Cerebrospinal fluid Profiles; CT: Computed tomography; MRI: Magnetic resonance imaging; BMRC: British Medical Research Council; IDSA: Infectious Diseases Society of America; med: Median; SD: Standard deviation; VPS: Ventriculoperitoneal shunts; WBC: White blood
} cell

\section{Acknowledgments}

The authors would like to thank the patients and their families for their participation and assistance.

\section{Authors' contributions}

FP mainly contributed to the conception and design. $M L$, $J$ and XD have been involved in drafting the manuscript. QG and YW have contribution to acquisition of data, give the consent to participants. XX and YJ have analyzed and interpreted data. ML, JL, FP and $Y J$ have revised the manuscript. All authors read and approved the final manuscript for publication.

\section{Funding}

This work was supported by Science and Technology Planning Project of Guangdong Province (2017B020230003). The funding bodies played no role in the design of the study and collection, analysis, and interpretation of data and in writing the manuscript.

\section{Availability of data and materials}

The data and materials used during the current study are available from the first author on reasonable request.

\section{Ethics approval and consent to participate}

This study was approved by the Ethics Committees of The Third Affiliated Hospital of Sun Yat-Sen University. The study was in compliance with the Declaration of Helsinki and its later amendments. All study participants provided written informed consent. Identifiable data involving the individuals in this study was encrypted.

\section{Consent for publication}

Not Applicable.

\section{Competing interests}

The authors declare that they have no competing interests.

\section{Author details}

${ }^{1}$ Department of Neurology, The Third Affiliated Hospital of Sun Yat-Sen University, Guangzhou 510630, Guangdong, China. 'Department of Neurology, Yuebei People' Hospital, Shaoguan 5120264, Guangdong, China.

Received: 28 April 2020 Accepted: 12 October 2020

Published online: 16 November 2020

\section{References}

1. Rajasingham R, Smith RM, Park BJ, Jarvis JN, Govender NP, Govender NP, Chiller TM, Denning DW, Loyse A, Boulware DR. Global burden of disease of HIV-associated cryptococcal meningitis an updated analysis. Lancet Infect Dis. 2017;17:873-81. https://doi.org/10.1016/S1473-3099(17)30243-8.

2. Pukkila-Worley R, Mylonakis E. Epidemiology and management of cryptococcal meningitis: developments and challenges. Expert Opin Pharmacother. 2008;9:551-60. https://doi.org/10.1517/14656566.9.4.551.

3. Pappas PG. Cryptococcal infections in non-HIV-infected patients. Trans Am Clin Climatol Assoc. 2013;124:61-79. https://doi.org/10.3390/jof5030071.

4. Portegies P, Solod L, Cinque P, Chaudhuri A, Begovac J, Everall I, et al. Guidelines for the diagnosis and management of neurological 
complications of HIV infection. Eur J Neurol. 2004;11:297-304. https://doi. org/10.1111/j.1468-1331.2004.00856.X.

5. Perfect JR, Dismukes WE, Dromer F, Goldman DL, Graybill JR, Hamill RJ, et al. Clinical practice guidelines for the management of cryptococcal disease: 2010 update by the Infectious Diseases Society of America. Clin Infect Dis. 2010:50:291-322. https://doi.org/10.1086/649858.

6. Brouwer AE, Rajanuwong A, Chierakul W, Griffin GE, Larsen RA, White NJ, et al. Combination antifungal therapies for HIV-associated cryptococcal meningitis: a randomised trial. Lancet. 2004;363:1764-7. https://doi.org/10. 1016/S0140-6736(04)16301-0.

7. Williamson PR, Jarvis JN, Panackal AA, Fisher MC, Molloy SF, Loyse A, et al. Cryptococcal meningitis: epidemiology, immunology, diagnosis and therapy. Nat Rev Neurol. 2017;13:13-24. https://doi.org/10.1038/nrneurol.2016.167.

8. Xu L, Liu J, Zhang Q, Li M, Liao J, Kuang W, et al. Triple therapy versus amphotericin B plus flucytosine for the treatment of non-HIV- and nontransplant-associated cryptococcal meningitis: retrospective cohort study. Neurol Res. 2018;40:398-404. https://doi.org/10.1080/01616412. 2018.1447319

9. Liu J, Chen Z, Li M, Chen C, Yi H, Xu L, et al. Ventriculoperitoneal shunts in non-HIV cryptococcal meningitis. BMC Neurol. 2018;18:58. https://doi.org/10. 1186/s12883-018-1053-0.

10. Vidal JE, Penalva de Oliveira AC, Dauar RF, Boulware DR. Strategies to reduce mortality and morbidity due to AIDS-related cryptococcal meningitis in Latin America. Braz J Infect Dis. 2013;17:353-62. https://doi.org/10.1016/j. bjid.2012.10.020.

11. British Medical Research Council. Streptomycin treatment of tuberculous meningitis. BMJ. 1948;1:582-97.

12. Azure TM, Grace MHG. New approaches to the diagnosis and treatment of cryptococcal meningitis. Semin Neurol. 2014;34:47-60. https://doi.org/10. 1055/s-0034-1372342.

13. Saag MS, Cloud GA, Graybill JR, Sobel JD, Tuazon CU, Johnson PC, et al. A comparison of itraconazole versus fluconazole as maintenance therapy for AIDS-associated cryptococcal meningitis. Clin Infect Dis. 1999;28:291-6. https://doi.org/10.1086/515110.

14. Dromer F, Mathoulin-Pélissier S, Fontanet A, Ronin O, Dupont B, Lortholary $\mathrm{O}$, et al. Epidemiology of HIV-associated cryptococcosis in France (1985-2001). AIDS. 2004;18:555-62. https://doi.org/10.1097/ 00002030-200402200-00024.

15. Segal BH, Herbrecht R, Stevens DA, Ostrosky-Zeichner L, Sobel J, Viscoli C, et al. Defining response to therapy and study outcomes in clinical trials of invasive fungal disease: mycoses study group and European Organization for Research and Treatment of Cancer consensus criteria. Clin Infect Dis. 2008;47:674-83. https://doi.org/10.1086/590566.

16. Zhu LP, Wu JQ, Xu B, Ou XT, Zhang QQ, Weng XH. Cryptococcal meningitis in non-HIV-infected patients in a Chinese tertiary care hospital, 1997-2007. Med Mycol. 2010;48:570-9. https://doi.org/10.3109/13693780903437876.

17. Concha-Velasco F, González-Lagos E, Seas C, Bustamante B. Factors associated with early mycological clearance in HIV-associated cryptococcal meningitis. PLoS One. 2017;12:e0174459. https://doi.org/10.1371/journal. pone. 0174459 .

18. Larsen RA, Bauer M, Thomas AM, Graybill JR. Amphotericin B and fluconazole, a potent combination therapy for cryptococcal meningitis. Antimicrob Agents Chemother. 2004;48:985-91. https://doi.org/10.1128/ AAC.48.3.985-991.2004

19. Pappas PG, Chetchotisakd P, Larsen RA, Manosuthi W, Morris ML, Anekthananon $\mathrm{T}$, et al. A phase II randomized trial of amphotericin B alone or combined with fluconazole in the treatment of HIV-associated cryptococcal meningitis. Clin Infect Dis. 2009;48:1775-83. https://doi.org/ $10.1086 / 599112$

20. Nussbaum JC, Jackson A, Namarika D, Phulusa J, Kenala J, Kanyemba C, et al. Combination flucytosine and high - dose fluconazole compared with fluconazole monotherapy for the treatment of cryptococcal meningitis: a randomized trial in Malawi. Clin Infect Dis. 2010;50:338-44. https://doi.org/ 10.1086/649861

21. Husain M, Jha DK, Rastogi M. Angiographic catheter: unique tool for neuroendoscopic surgery. Surg Neurol. 2005;64:546-9. https://doi.org/10. 1016/j.surneu.2005.04.037.

22. Iwashita T, Kitazawa K, Koyama J, Nagashima H, Koyama T, Tanaka Y, et al. A saccular-like dissecting aneurysm of the anterior cerebral artery that developed 2 years after an ischemic event. Surg Neurol. 2005;64:538-41. https://doi.org/10.1016/j.surneu.2005.01.023.
23. Pappas PG. Management cryptococcal meningitis is about handling the pressure. Clin Infect Dis. 2005;40:480-2. https://doi.org/10.1086/427222.

24. Bicanic T, Brouwer AE, Meintjes G, Rebe K, Limmathurotsakul D, Chierakul W, et al. Relationship of cerebrospinal fluid pressure, fungal burden and outcome in patients with cryptococcal meningitis undergoing serial lumbar punctures. AIDS. 2009;23:701-6. https://doi.org/10.1097/QAD. 0b013e32832605fe.

25. Jarvis JN, Bicanic T, Loyse A, Namarika D, Jackson A, Nussbaum JC, et al. Determinants of mortality in a combined cohort of 501 patients with HIVassociated Cryptococcal meningitis: implications for improving outcomes. Clin Infect Dis. 2014;58:736-45. https://doi.org/10.1093/cid/cit794.

26. Robinson PA, Bauer M, Leal MA, Evans SG, Holtom PD, Diamond DA, et al. Early mycological treatment failure in AIDS-associated cryptococcal meningitis. Clin Infect Dis. 1999;28:82-92. https://doi.org/10.1086/515074.

27. Hung CW, Lin WC, Chang WN, Su TM, Kung CT, Tsai NW, et al. Risk factors and outcomes of cerebrospinal fluid overdrainage in HIV-negativepatients with cryptococcal meningitis after the ventriculoperitoneal shunting procedure. J Microbiol Immunol Infect. 2018;51:545-51. https://doi.org/10. 1016/j.jmii.2017.06.002

28. Baddley JW, Thompson GR 3rd, Riley KO, Moore MK, Moser SA, Pappas PG. Factors Associated With Ventriculoperitoneal Shunt Placement in Patients With Cryptococcal Meningitis. Open Forum Infect Dis. 2019;6: ofz241. https://doi.org/10.1093/ofid/ofz241 eCollection.

\section{Publisher's Note}

Springer Nature remains neutral with regard to jurisdictional claims in published maps and institutional affiliations.
Ready to submit your research? Choose BMC and benefit from:

- fast, convenient online submission

- thorough peer review by experienced researchers in your field

- rapid publication on acceptance

- support for research data, including large and complex data types

- gold Open Access which fosters wider collaboration and increased citations

- maximum visibility for your research: over $100 \mathrm{M}$ website views per year

At BMC, research is always in progress.

Learn more biomedcentral.com/submissions 